\title{
Endonasal Dacryocystorhinostomy: A Comparative Study between Conventional Mucosal Flap and Silicone Stenting
}

\author{
${ }^{1}$ Chaitry K Shah, ${ }^{2}$ Neena H Bhalodiya
}

\begin{abstract}
Aims: Recurrent stenosis and closure of neostium are considered a major factor for surgical failure in endoscopic dacryocystitis (endo-OCR). The main objective of this study is to evaluate the role of silicon stent in maintaining the patency of neostium and compare it with the conventional mucosal flap technique.
\end{abstract}

Materials and methods: Endodacryocystorhinostomy (DCR) were done in 60 eyes. In 30 eyes only mucosal flap was created and in other 30 silicon stent tubes were used. All patients were taken under general anesthesia.

Results: In our study, 90\% success in syringing patency was seen in the group with mucosal flap only and $100 \%$ success was seen in silicon stenting at 6 months of follow-up.

Conclusion: Significant difference in endo-DCR success rates were seen with the use of stenting in our study especially in revision cases.

Clinical significance: It is really important to provide success in revision cases of DCR surgery, and silicone stenting helps to obtain that according to our study.

Keywords: Endoscopic dacryocystorhinostomy, Nasolacrimal duct obstruction, Neo-ostium, Silicone tube stent.

How to cite this article: Shah $\mathrm{CK}$, Bhalodiya $\mathrm{NH}$. Endonasal Dacryocystorhinostomy: A Comparative Study between Conventional Mucosal Flap and Silicone Stenting. Clin Rhinol An Int J 2018;11(1):15-17.

Source of support: Nil

Conflict of interest: None

\section{INTRODUCTION}

Dacryocystorhinostomy (DCR) surgery is a procedure that aims to eliminate fluid and mucus retention within the lacrimal sac and to facilitate tear drainage to relieve watering from eyes. Epiphora is a common presenting complaint of patients referred to ophthalmology OPD. Some of these patients are referred to ENT OPD rule out any nasal cause. Evaluation with nasal endoscopy and syringing provides insight into the underlying disorder in the lacrimal apparatus.

\footnotetext{
${ }^{1}$ Senior Resident, ${ }^{2}$ Professor and Head

1,2Department of ENT, GMERS Medical College, Ahmedabad, Gujarat, India

Corresponding Author: Chaitry K Shah, Senior Resident, Department of ENT, GMERS Medical College, Ahmedabad, Gujarat, India, e-mail: drchaitryent@yahoo.com
}

The endonasal approach was introduced by Caldwell in $1893 .{ }^{1}$ With the advent of Hopkins rod system the nasal and lacrimal anatomy has been elucidated in great detail. The first endo-DCR was done by McDonough and Meiring. ${ }^{2}$ In a recent review of results after DCR in adults, the success rate of endo-DCR was found to range from 84 to $94 \%{ }^{3}$ The endoscopic approach to lacrimal sac has distinct advantages regarding less trauma and better cosmetic acceptability. ${ }^{4}$ The mid and low lacrimal system blockage can be successfully addressed with the endonasal Dacryocystorhinostomy (endo-OCR). A transcanalicular silicone stent may be placed at the time of surgery to maintain patency of the DCR ostium. There has been some controversy regarding ostium closure due to granulations following stent insertion. ${ }^{5,6}$

\section{MATERIALS AND METHODS}

Between July 2014 to July 2015 endo OCR was performed on total 60 eyes which were divided into two groups of 30 each, out of which one group of 30 underwent conventional mucosal flap endo-OCR and 30 underwent silicon stenting along with. Twenty-eight patients were male and 26, female of age group 35-72 years. Epiphora and chronic dacryocystitis were presenting symptoms. A few patients also presented with burst open pyocele.

Informed consent was taken from all the patients.

\section{Inclusion Criteria}

- Primary and revision surgery

- Adult patients (>18 years) with nasolacrimal duct obstruction

\section{Exclusion Criteria}

- Pediatric cases

- Cases with comorbid medical history

All patients underwent a complete ophthalmic and endoscopic nasal examination for anatomical variations and associated pathology. The operation was performed under general anesthesia.

Decongestion of the nasal mucosa was done by nasal wicks soaked in $4 \%$ xylocaine and adrenaline 1:100 000 solution which was kept anterior and medial to the middle turbinate for 10 minutes. A $2 \%$ lignocaine with 1:100 000 adrenaline solution was injected into the nasal 
mucosa just superior and anterior to the attachment of the middle turbinate under endoscopic visualization. We used a 0-degree endoscope for the surgery. During the surgery, a mucosal flap was elevated from the region just anterior to the middle turbinate in the lateral nasal wall. The flap was elevated at approx $5 \mathrm{~mm}$ superior to the attachment of MT. The mucosal flap was elevated medially and preserved by tucking in MM. The bone underlying the flap was constituted by the anterior lacrimal crest of the maxilla anteriorly and the lacrimal bone posteriorly. The groove between the lacrimal and maxilla palpated with a freers elevator. The lacrimal bone was easily dissected and removed and lacrimal crest removed by OCR punch. The medial wall of exposed lacrimal sac was incised with a stab knife and anterior and posterior flaps were created. The mucosal flap was repositioned around the bony ostium to cover all exposed bone in all the patients. The main concerns were proper flap position, wide bone removal and less injury to surrounding structures. Bicanalicular silicone intubation (Lacrimal intubation set) was performed in 30 eyes. The stainless steel probes attached to the silicone tubing were retrieved under endoscopic visualization by straight Blakesley. Both ends of the tubing were knotted together stretched and cut. The silicone stent was removed after 12 weeks.

\section{RESULTS}

Patients were followed up for a minimum of 6 months.

Success was considered if the patient was asymptomatic for 3 months as well as if patency was thereby sac synnging.

Of the 60 procedures performed 30 patients underwent a surgical procedure with just a mucosal flap and other 30 had silicone stenting. Total 12 cases were a revesion DCR out of which seven cases underwent silicon stenting and five cases were done by mucosal flap technique (Table 1).

Endoscopic examination of the nose was done at each follow up of all the patients and specifically granulation tissue and synechia formation was looked for (Table 2).

In above table failure two cell value is ' 0 ' so $p$ value cannot be calculated the $p$ value, but by observation, you can interfere than there is no difference in success

Table 1: Primary and revision cases in each group

\begin{tabular}{llll}
\hline Technique & Primary cases & $\begin{array}{l}\text { Revison } \\
\text { cases }\end{array}$ & Total \\
\hline Mucosal flap & 25 & 5 & 30 \\
Silicone & 23 & 7 & 30 \\
stenting & & & \\
\hline
\end{tabular}

rate between this two methods in primary cases (Table 3).

Fisher's test was applied $<p$ value: 0.04 significant The success rate in 30 cases that had undergone conventional mucosal flap endoscopic intranasal DCR was in 27 (90\%). Thirty of thirty cases (100\%) with stenting were successful. The two patients who underwent failure in conventional mucosal flap technique were both revision cases (Figs 1 and 2).

\section{DISCUSSION}

The main advantages over external approaches are, scarless surgery, least traumatic, precise technique and less morbidity. The added advantage of performing endo-

Table 2: Success in primary cases

\begin{tabular}{llll}
\hline Technique & Total & Success & Failure \\
\hline Mucosal flap & 25 & 25 & 0 \\
Silicone stenting & 23 & 23 & 0 \\
\hline
\end{tabular}

\begin{tabular}{llll}
\hline \multicolumn{4}{c}{ Table 3: Success in revision cases } \\
\hline Technique & Total & Success & Failure \\
\hline Mucosal flap & 5 & $2(40 \%)$ & $3(60 \%)$ \\
Silicone stenting & 7 & $7(100 \%)$ & $0(0 \%)$ \\
\hline
\end{tabular}

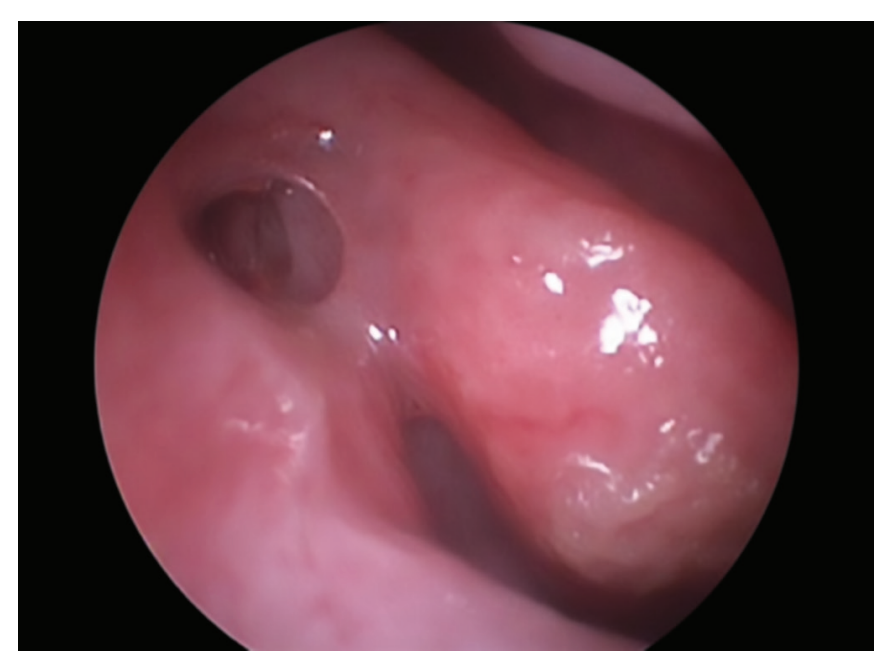

Fig. 1: Neostium after conventional mucosal flap surgery

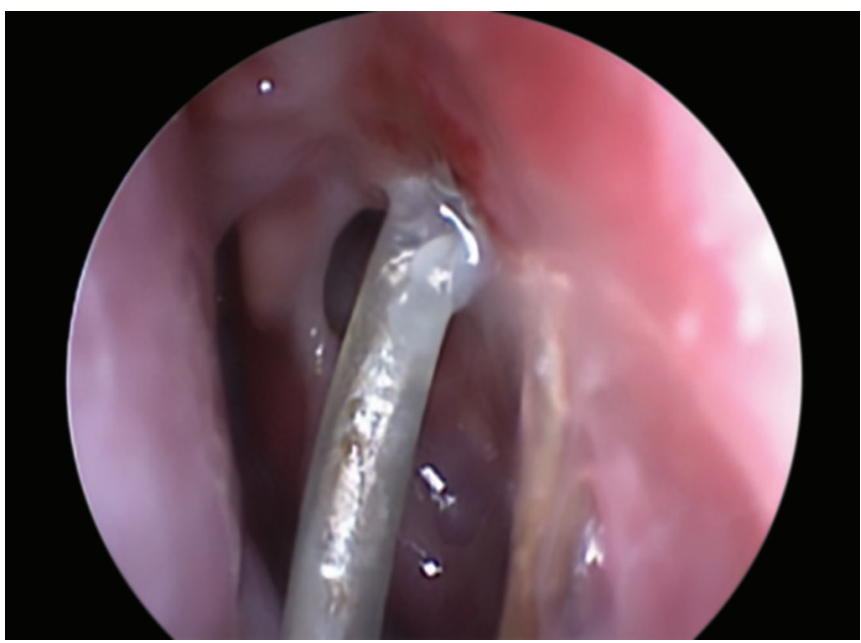

Fig. 2: Silicone stent in situ at 12 weeks postsurgery 
scopic DCR is also the preservation of medial canthal ligament of an eye. So lacrimal pump function is also preserved.

The success rate of endo-DCR is about $90 \%$, which is comparable to external OCR. Linberg et al. ${ }^{7}$ showed that a mean intranasal ostium size of $1.8 \mathrm{~mm}$ was enough to be successful in external OCR. There have been chances of failure in endo-DCR because direct suturing cannot be done at the site of the opening of the lacrimal sac. Also as there is no continuous flow of fluid or enough pressure to maintain the surgically created fistula. A silicone stent was needed for some time after endoscopic procedures. The minimal reduction in the size of the healed intranasal ostium after surgery is the result of a normal wound healing response. ${ }^{8}$

Analysis of Boush et al. ${ }^{9}$ series showed that the majority of the surgical failures occurred within 4 months after endoscopic surgery. A similar finding was also seen in Kong et al. ${ }^{10}$ study. Woog et al. ${ }^{11}$ also reported that the average onset of failure was 7.5 weeks postoperatively (2-14 weeks). ${ }^{11}$

Closure of the neosteum site with granulation tissue and growth of mucosa occurred in two cases, causing failure of surgery. The success rates of endoscopic endonasal DCR must attain those of external DCR to become an effective alternative. Various methods such as silicone sponge implant, gelfoam-thrombin stent, and C flex catheters were used to increase the success of dacryocystorhinostomies. ${ }^{10}$

In this study, the main cause of restenosis was gradual closure of the osteotomy site by mucosal in growth and improper position of the flap leading to covering of the osteotomy site.

\section{CONCLUSION}

Conventional mucosal flap technique is very good for primary cases. And silicon stenting has an upper edge on conventional mucosal flap technique for success in revision cases.

\section{CLINICAL SIGNIFICANCE}

As this study suggests revision cases are very crucial when the result is concerned. Obtaining sure success in every surgical procedure is very important for any surgeon especially in revision cases. Thus when silicon stenting used especially in revision cases greater success ratio is expected.

\section{REFERENCES}

1. Caldwell GW. Two new operations for obstruction of the nasal duct. N Y J Med 1893;57:581-582.

2. McDonough M, Meiring JH. Endoscopic transnasaldacryocystorhinostomy. J Laryngol Otol 1989;103:585-587.

3. Leong SC, Macewen CJ, White PS. A systematic review of outcomes after dacryocystorhinostomy in adults. Am J Rhinol Allergy 2010;24:81-90.

4. Korkut AY, Teker AM, Yazici MZ, et al. Surgical outcomes of primary and revision endoscopic dacryocystorhinostomy. J Craniofac Surg. 2010;21(6):1706-1708.

5. Woog JJ, Metson R, Puliafito CA. Holmium:YAG endonasal laser dacryocysto-rhinostomy. Am J Ophthalmol 1993;116: 1-10.

6. Unlu HH, Toprak B, Aslan A, et al. Comparison of surgical outcomes in primary endoscopic dacryocystorhinostomy with and without silicone intubation. Ann Otol Rhinol Laryngol 2002;111:704-709.

7. Linberg JV, Anderson RL, Bumsted RM, et al. Study of intranasal ostium in external dacryocystorhinostomy. Arch Ophthalmol 1982;100:1758-1762.

8. David AL. Antifibrosis agents and glaucoma surgery. Invest Ophthalmol Vis Sci 1994;35:3789-3791.

9. Boush GA, Bradley NL, Dortzbach RK. Results of endonasal laser-assisted dacryocystorhinostomy. Ophthalmology 1994;101:955-959.

10. Kong YT, Kim TI, Kong BW. A report of 131 cases of endoscopic laser lacrimal surgery. Opthalmology 1994;101(11):1793-1800.

11. Woog JJ, Metson R, Puliafito CA. Holmium:YAG endonasal laser dacryocystorhinostomy. Am J Opthalmol 1993;116(1):1-10. 